\title{
XXXVIII. On the mensuration of timber
}

\section{Mr. John Farey}

To cite this article: Mr. John Farey (1804) XXXVIII. On the mensuration of timber, Philosophical Magazine Series 1, 19:75, 213-222, DOI: 10.1080/14786440408676555

To link to this article: http://dx.doi.org/10.1080/14786440408676555

$$
\text { 曲 Published online: } 18 \text { May } 2009 .
$$

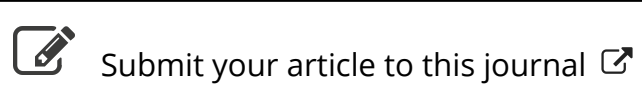

\footnotetext{
III Article views: 4
}

Q View related articles ¿ 


\title{
[ $\begin{array}{ll}213 & ]\end{array}$
}

\section{On the Mensuration of Timler. By Mr. JOH N FAREY.}

To the Editor of the Philosophical Magazine.

\begin{abstract}
SIR,
$T_{\text {HE following paper was written at the particular request }}$ of the very intelligent nobleman to whom it is addressed, and who has since expressed a wish that I would publish it, on account of the importance of the subject to land-owners and growers of timber. By giving it a place in your Magazine, you will greatly oblige, sir,

Your obedient humble servant,

June 15,1804 . JOHN FAREX.
\end{abstract}

\section{To the Right Honourable Lord SHefrield, President of the Bourd of Agriculture, $\mathscr{G}^{\circ} \mathrm{c}$.}

\section{MY LORD,}

Is complying with the wish which your lordship did the the honour to express, to receive a communication from me on the subject of timber, and particularly on the customary modes of measuring it for sale, it is necessary. I should apologize for enumerating many things, for the sake of connecting the subject, which have been often before published, and are too well known to your lordship and most other growers of timber, to have otherwise required repeating. Timber in large quantities is generally sold by the load, and in smaller quantities by the foot, without its being generally understood or adverted to, that in reality three different quantities pass under the denomination of foot, and the same of load: first, the cubic foot of 1798 cubic inches; second, the foot round measure, varying, according to the shape or dimensions of the different parts of the tree, from about 2200 to about 2500 eubic inches; and third, the foot square measure, varying also, according to the shape of the tree, from about 1360 to about 2000 cubic inches. In each of these cases the load is equal to 50 of the respective feet.

The first or cubic foot occurs in measuring square sawed timber, or what is called die-square timber, and plank, scantling, \&c. (as also in the measure of hewn or sawn stone-work), and is found by taking the length, breadth, and depth of the piece, and multiplying these three dimensions together. For example: suppose a piece of square

Vol.19. No. 75. August 1804. Q 
timber, as fig. 1, (Plate V.) to be in length, A B or CE, 25 feet in breadih, AC or BE, 24 inches; and in depth, AD or EF, 12 inches; then the breadth 24 multiplied by the depth 12, gives 288 superficial inches (144 of which make a superficial or plane foot) for the area or measure of the end, which being divided * by 144 gives two superficial feet, which, multiplied by the length 25 , gives 50 cubic feet, or one load, for the measure or content. Planks and boards are also reduced to this measure by taking their length, breadtb, and thickness.

The second, or foot round measure, occurs in the common method used in measuring round timber, or whole trees, either while standing or after being felled. If the tree tapers regularly from the bottom or but, to the top or smaller end, as in fig. 2, it is measured by taking the length $A B$, and thereby finding the middle $\mathrm{C}$, and then by a string taking the circumference or girt at $\mathrm{C}$ and applying the same to a carpenter's rule to take the inches $\phi$, one quarter of which is called the quarter girt, or more commonly the girt; then the girt is multiplied by itself, divided by 144 to reduce it to fect, and these multiplied by the length, to obtain the content. For example: suppose a tree to be in length $\mathrm{AB}$ 25 feet, and that its circumference in the middle at $\mathrm{C}$ is 68 inches; then the fourth of this, or 17 inches, is the girt, and the girt 17 inches multiplied by 17 is 289 inches, and this divided by 144 is two feet, (neglecting the small fraction 1-144th of a foot, ) which multiplied by 25 feet, the length, gives the measure or content 50 feet round measure, or one load. Now since the girt in the mildle at $\mathrm{C}$ remaining the same, the circumferences at the two ends may and do in practice vary, in all proportions, from that of being only 6 inche $i$ girt or 24 inches circumference af the smallest end $B$, fig. 3 ; the but $A$ at the same time being very large, and the tree then differing but little from the cone $A \bar{D}$, to the case in which the two ends. $A$ and $B$ are

* In this and the following examples, I have reduced the area into feet (by dividing by 144 ) previous to multiplying by the longth, as better calculated for showing the reason of the operation; hut in practice it is more usual and ready to multiply by the length previous to dividing by 144.

$\uparrow$ A string is constantly used by the buyers of timber: but the $\mathrm{gra}^{3}-$ duated tapes incented for the purpose, and made by Cary. optician, in the Strand, arc more exacr, and much more expecitions and casy in practice: and here I would remark, that the allowance of the girt for the bark ought to be $6 \frac{1}{7}$ times the thickness of the bark, and not any certain proporion of the girt, much less a fixed number of inches, as some buyers will contend. 

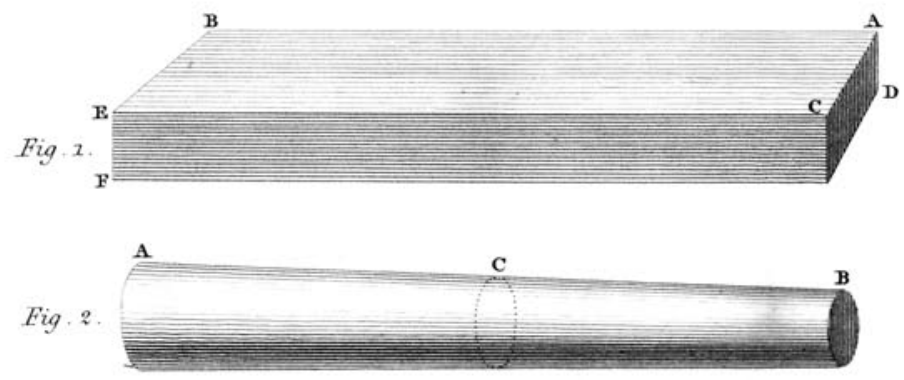

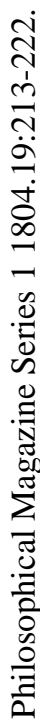
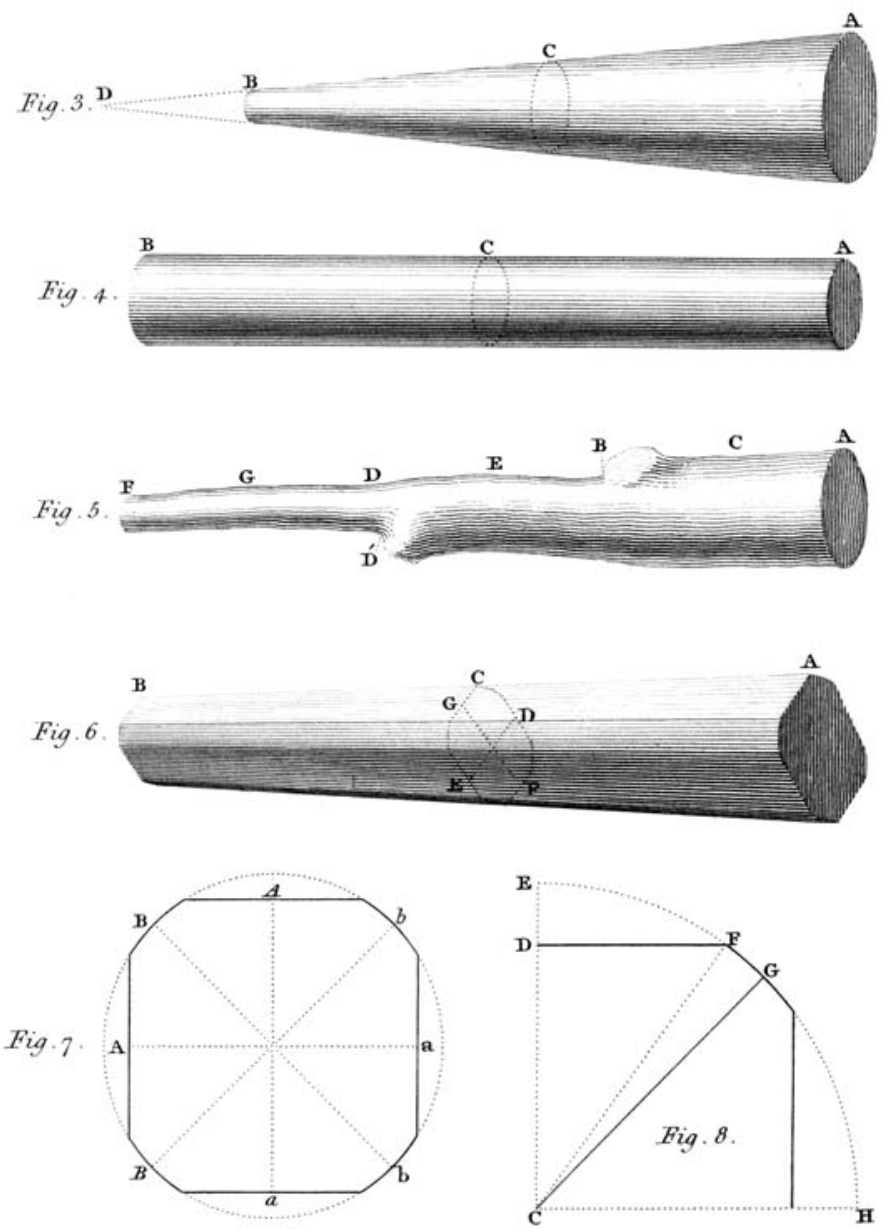
equal, or the tree a cylinder, as fig: 4 ; a source of uncertainty and error hereby arises, besides the other source of error in taking 1-4th of the circumference to be the side of the square equal to the circle: these causes operate differently in different trees, so as to cause the real content of a foot of timber round measure to vary, as before stated, from about 2200 to about 2500 cubic inches, always exceeding the truth by more than one-fourth part of the whole.

In case the tree does not taper regularly as above described, but owing to knots or branches tapers irregularly in different parts, as in fig. 5 , having at the points $\mathrm{B}$ and $\mathrm{D}^{\prime}$ what are called stops or knots, occasioning the tree to lessen suddenly at these places; in such case the tree is measured at three lengths; first taking the length $A B$ and girt at $C$, then the length $B D$ and girt at $E$, and lastly the length $D F$ and girt at $\mathrm{G}$; and calculating the three pieces separately by the above method, the three contents are added together for the content or ineasure of the whole tree*.

The third, or foot square measure, occurs in measuring timber which has been hewn or sided in part, as in fig. 6 ; the transverse section of such a tree being in fact an eightsided figure, contained under four straight lines and four curved ones, part of the circumference of the tree; and trees are never so much hewn or sided as to take out the corners entirely, for then they would be called die-square; as in the first case. The method of measuring here is to take the length $A B$, and thereby to determine the middle point $C$, and, instead of girting it there, its depth DE is taken with a pair of calliper compasses, which are afterwards applied, to a carpenter's rule to get the inches therein: in like manner its breadth FG is taken; and if these differ; they are added together and the half of their sum taken as

- In the above tree, if the larger picce is in length $A B_{I 7}$ feet and Its girt at $\mathrm{C}_{24}$ inches, the middle picce in length $B \mathrm{D}_{17}$ fet and its girt at $\mathrm{E}$ be 15 inches, and the smaller piece in length $D F$ I 7 feet and its girt at $G$ be 6 inches, then the who!e length, or three times 17 , being 51 feet, and the girt at its riddle 15 inches, (being also in this case the third of the sum of the three girts, or $\frac{24 \times 15 \times 6}{3}$ ); therefoic 25 multiplied by 15 , this divided by 144 , and then multiplied by 51 , gives $79 \frac{1}{2}$ feet as the content when measured in one piece: but if this tree be measured in three lengths as above directed, then $24 \times 24 \div 144 \times 17=68$ feet the content of the greater prece, also $15 \times 15 \div 144 \times 17=26^{3}$ feet the content of the middle picce. an $6 \times 6 \div 144 \times 17=4$ feet the content of the smaller piece; the sum of these three or $68+26 \frac{1}{2}+$ $4 \frac{1}{7}=9 \delta \frac{3}{4}$ feet for the content; when measured as three picces, exceeding she other by 19.9 feet. 
the calliper of the tree : this calliper is multiplied by itself, divided by 144 to reduce it to feet, and these multiplied by the length to get the content or measure of the tree. For example: suppose a hewn tree to be in length $A B 25$ feet, and at the middle $\mathrm{C}$ to calliper in depth $17 \frac{1}{2}$ inches, and in breadth $16 \frac{1}{2}$ inches, ther is 17 inches the calliper: this multiplied by 17 gives 289 , and this divided by 144 gives two feet (neglecting a small fraction), which multiplied by the length 25 feet, gives 50 feet square measure, or one load. On account of the tapering or unequal dimensions of the two ends, also on account of the unequal manner in which timber is hewn, some trees having only just a chip taken off their sides, and others being hewn till nearly diesquare, and in all the intermediate degrees; and further, on account of the loss of the corners, the real quantity of the foot square measure is still more uncertain and vague than the foot round measure, for it varies from about 1360 to about 2000 cubic inches, being sometimes below and sometimes above the truth : but it should be remarked, that the cubic inches mentioned above, as the limits within which the foot round measure and the foot square measure vary, is only on a supposition that the sides of the tree are regular, or that it has no particular swelling in the middle or girting place to cause it to girt or calliper more, or hollow to cause it to girt or calliper less, than it would if the tree were regular; for in these cases (which too frequently occur in practice) the round measure and square measure are often still more wide of the truth.

If a sided or hewn tree does not taper regularly throughout, or has the knots or stops described above in the case of round timber, then the tree is measured in different lengths, and the contents of the parts are added together for the content of the whole tree, as in the case of round timber. In like manner, the branches reserved and sold for knees or braces in ships, barges, \&c. either round or hewn, are measured in two lengths.

The first of the above, or cubic measure, will prove consistent with the weight: thus, if 10 cubic feet of a tree weigh $578 \mathrm{lb}$., 30 cubic feet of the same tree will weigh $1734 \mathrm{lb}$. ; but in either of the other measures it is but in some very rare cases that 30 feet of a tree will be found to weigh three times as much as 10 feet of the same tree cven when measured by the same mode! The difference in the weights of the round measure and the square measure is so considerable, that for the purposes of freight or carriage it is an established custom that 40 feet of round timber make a load, 
a load, but of square or hewn timber fifty feet make a load.

Notwithstanding the glaring inconsistencies of the two last methods, they are established, and from their facility in practice, especially to those who are expert at operating with duodecimals, and to others when aided by Hoppus tables and others in use for casting up or performing the numerical operation, or by the still more facile operations of the slide rule, I have no hopes of speedily seeing them laid aside and more correct methods introduced; they will in all probability continue as long as the other heterogeneous, multifarious, and absurd denominations of our measures and weights*. In the mean time it is of importance to the grower, of oak timber in particular, to be able to calculate, in a lot containing a certain number of loads or feet of tim. ber, measured in the round, or as it is generally sold by the grower, how many loads or feet the same lot will measure when hewn in any determinate manner $(i . e$. when the ratio or proportion between $\mathrm{A} a$ and $\mathrm{Bb}$, fig. 7 , is known), and afterwards measured by callipering it, being the mode in which it is measured when purchased in his majesty's dock-yards, and by the private ship and barge builders, \&c. in London. As $I$ am not aware that any rules have been laid down, or that any table for this purpose has been published, I have constructed the following table, consisting of four columns; the first containing the ealliper $\mathrm{Aa}$ or $A \alpha$ of hewn timber at the middle or girting place, (see fig. 7 ,) wherein the diameter $\mathrm{Bb}$ or $B b$ is 1 or 1.00 ; the numbers herein begin at 70 or 70 -100dths of the diameter, (which is something less than a tree can be hewn without absolute waste,) increasing in a regular order by $1-100 \mathrm{dths}$ to $1 \cdot 00$, or the case in which the least possible thickness is hewn off the tree : but it must be remarked in this column, that between this regular series of numbers, $\cdot 70, \cdot 71, \cdot 72$, \&c. other numbers are inserted in their proper places, but carried to a greater number of places of decimals, for showing more exactly the proportions in some particular cases mentioned in

* The true content of any round tree might be found by the help of tapes and tables constructed for the purpose, in as short a time as it can be measured by the present mode with a string and rule; and simple tables might be made for the allowance for the corners generally wanting in hewn timber, and for showing its true or cubic content. Improved slide-rules might also he used for the above purposes, instead of tables. A very imple instrument has been made, and used with great success by a friend of mine, $\mathrm{M} r$. Bevan of Leighton Buzzard, for hinding the true content, or the customary content, allowing for the bark, $\alpha$. 
the fourth column; thus 7071068 , or $\frac{7071068}{10000000}$ of the di. ameter $\mathrm{Bb}$ will be the calliper $\mathrm{Aa}$, when the tree is hewn to the inscribed square, or the most that it can be hewn without waste.

The second column shows the ratio or proportion, expressed in decimals, between the content of any tree measured in the round by girting it, expressed by 1 or unity, and the same tree hewn in any proportion, expressed by its calliper in the first column, and then measured as square timber by callipering it, or the ratio between the foot square measure and the foot round measure, or between the loads of the same denominations. The third column shows the proportionate price that the same timber, measured by the two methods, ought to bear (exclusive of the expense of hewing, carriage, \&c.), expressed in shillings and decimals, assuming the price of round timber to be 100 sbillings (51.) for the convenience of calculating. In the fourth and last column are mentioned the particular proportions of the numbers before mentioned against which they stand: thus-the " side of the inscribed square". is also " $1-4$ th of the peri-

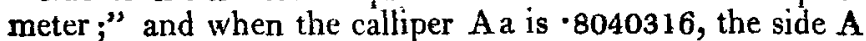
or $A$ is " $1-5$ th of the perimeter," or sum of all the sides $\mathrm{A}, \mathrm{B}, A, b, \mathrm{a}, \mathrm{b}, \mathrm{a}, B$, or outline of the figure; also "decrease of $1-5$ th in content". against 7024815 , shows that in this case the square measure of any tree is 1-5th part less than the round measure of that same tree; at $\mathbf{7 8 5 3 9 8 2}$ they are equal, and at .9619124 the square measure exceeds the round measure by half! In little more than in this last proportion is the small timber generally hewn, which is used by the barge-builders, carpenters, coopers and others in London; and in the trade, the prices per load or foot of round and hewn timber vary nearly in proportion thereto. 
On the Mensuration of Timber.

\begin{tabular}{|c|c|c|c|}
\hline $\begin{array}{l}\text { The calliper } \\
(\text { A a }) \text { of hewn } \\
\text { Timber, the } \\
\text { diameter }(\mathrm{B} b) \\
\text { being }=1.00 .\end{array}$ & $\begin{array}{l}\text { The Content } \\
\text { square Med- } \\
\text { sure, its Con- } \\
\text { tent round } \\
\text { Measure. } \\
\text { being } 1 .\end{array}$ & $\begin{array}{c}\text { Price of } \\
\text { hewn Timber, } \\
\text { that of round, } \\
\text { being } 100 .\end{array}$ & Proportions, \&c. \\
\hline ro & $\cdot 7943579$ & $125 \cdot 88784$ & \\
\hline$\cdot 7024815$ & 8 & $125 \cdot 00000$ & decrease of $1-5 \mathrm{th}$ in content \\
\hline$\cdot 7071068$ & .8105694 & $123 \cdot 37006$ & side of inscribed square, and \\
\hline .71 & .8172162 & $124 \cdot 36662$ & side $=1-4$ th of perimeter \\
\hline$\cdot 7169672$ & .83983333 & $120 \cdot 00000$ & decrease of $1.6 \mathrm{th}$ \\
\hline$\cdot 72$ & .8403984 & 118.99116 & \\
\hline 7271375 & .8571429 & $116 \cdot 66667$ & decrease of $1-7$ th \\
\hline 73 & .8690050 & 115.75345 & \\
\hline$\cdot 7346727$ & .875 & 114.28568 & decrease of $1-8 \mathrm{th}$ \\
\hline$\cdot 71$ & $\cdot 8877354$ & $112 \cdot 64618$ & \\
\hline 7404805 & $\cdot 888888$ & $112 \cdot 50000$ & decrease of $1.9: h$ \\
\hline$\cdot 74,309 \pm 0$ & $\cdot 9$ & $111 \cdot 11111$ & decrease of $1-10$ th \\
\hline$\cdot 75$ & .9118906 & $109 \cdot 66228$ & \\
\hline$\cdot 76$ & .9363696 & $106 \cdot 79540$ & \\
\hline$\cdot 77$ & .9611730 & $104 \cdot 03958$ & \\
\hline 78 & .9863010 & $101 \cdot 388 \subseteq 3$ & \\
\hline$\cdot 7853982$ & 1.000000 & $100 \cdot 00000$ & calliper $=1-4 t h$ of circumfe- \\
\hline .79 & $1 \cdot 011753$ & $98 \cdot 83839$ & rence, and eyual contents \\
\hline$\cdot 80$ & 1.057529 & 90.38287 & \\
\hline$\cdot 8040316$ & $1 \cdot 048013$ & 95.41872 & side $=1-5$ th of perimcter \\
\hline 81 & 10033629 & $94 \cdot 01774$ & 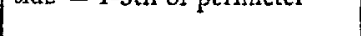 \\
\hline$\cdot 82$ & 1,090054 & 91.73856 & \\
\hline .8237824 & $1 \cdot 1$ & 90,90909 & 1-10th increase \\
\hline .8278324 & $1 \cdot 111111$ & $90 \cdot 00000$ & 1-9th increase \\
\hline 83 & $1 \cdot 116903$ & $89 \cdot 54134$ & 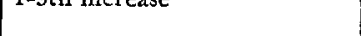 \\
\hline .8330404 & $1 \cdot 195$ & 88.88889 & 1-8th increase \\
\hline .8396260 & $1 \cdot 142857$ & $87 \cdot 50000$ & 1-7th increase \\
\hline-84 & $1 \cdot 143875$ & 87.42210 & \\
\hline$\cdot 8483270$ & $I \cdot 166667$ & $85 \cdot 71428$ & 1-6th increase \\
\hline .85 & 1.171272 & 85.37722 & \\
\hline-86 & $1 \cdot 198995$ & 83.40322 & \\
\hline-8603606 & $1 \cdot 2$ & $83 \cdot 33333$ & 1-5th increase \\
\hline .8618760 & $1 \cdot 204231$ & 83.04054 & side $=1-6$ th of perimeter \\
\hline-87 & $1 \cdot 227040$ & 81.49692 & \\
\hline 8781018 & 1.25 & $80 \cdot 00000$ & 14 th increase \\
\hline$\cdot 88$ & $1 \cdot 255410$ & 79.65525 & \\
\hline$\cdot 8862271$ & $1 \cdot 273240$ & 78.53980 & side of square equal to the \\
\hline 89 & $7 \cdot 284104$ & $77 \cdot 87530$ & circle \\
\hline .8980504 & 1.307439 & 76.48537 & side $=1-7$ th of perimeter \\
\hline$\cdot 90$ & $1 \cdot 313122$ & 76.15437 & \\
\hline 9068998 & $I \cdot 333933$ & $75 \cdot 00000$ & $1-3 d$ increase \\
\hline$\cdot 91$ & $1 \cdot 342465$ & 74.48983 & \\
\hline 92 & $1+372132$ & 72.87930 & \\
\hline$\cdot 9218736$ & $1 \cdot 377726$ & 72.58335 & side $=1-8 \mathrm{th}$ of perimeter \\
\hline$\cdot 93$ & $1 \cdot 402123$ & 71.32042 & \\
\hline$\cdot 9382994$ & 1.427259 & 70.06433 & side $=1-9$ th of perimeter \\
\hline .94 & 1.432438 & 69.81105 & \\
\hline$\cdot 95$ & $1 \cdot 463078$ & $68 \cdot 34906$ & \\
\hline .9500692 & $\mathrm{~J} \cdot 163291$ & $68 \cdot 33913$ & side $=1-10$ th of perimeter \\
\hline$\cdot 95$ & $1 \cdot 494041$ & 66.99255 & 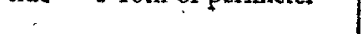 \\
\hline 9619124 & $1 \cdot 5$ & 66.66666 & $\frac{1}{2}$ increase \\
\hline .97 & 1.525329 & 65.55962 & \\
\hline$\cdot 98$ & 1.556942 & 64.22847 & \\
\hline .99 & $1 \cdot 588878$ & 62.93749 & \\
\hline 1.00 & $1 \cdot 621139$ & $61 \cdot 68503$ & $\begin{array}{l}\text { side }=\mathrm{O}_{2} \text { or circumscribing. } \\
\text { square }\end{array}$ \\
\hline
\end{tabular}


For example: suppose a hewn tree of any length, and that when callipered in the middle, on the angles or corners, or in the directions $\mathrm{Bb}$ and $B b$, fig. 7 , the same are shown by the rule to be $26 \frac{1}{4}$ and $25 \frac{3}{4}$ inches; add these together and take the half thereof, and we have 26 inches for

the

The mathematical reader will readily perceive the mode of calculating the content of a tree, either by the round or girt method or by the square or calliper method, to be the same, except in determining the area of the section at the girting place; and that the numbers in the second column of the above table, cxpressing the content square measure in different cases when the' round measure is unity, do ex press also the ratio of the areas of the girting or middle sections in each case : thus, in the first line of the table $\cdot 70+$ $\cdot 70=\cdot 49$ is the calliper area, and $\frac{3.141593 \times 3.141593}{4 \times 4} \times$ $\cdot 6168503$ is the girt area; whence, as $\cdot 6168503: 1:: \cdot 49$ : .7943579 the number in column the second : and thus the numbers answering to $\cdot 71,: 72, \cdot 73$, \&c. were determined. In the second line of the table, as there is to be a decrease of 1.5 th or $2-10$ ths in the content, we have given 8 for the number in the second column; whence, as $1: \cdot 6168503$ $:: \cdot 8: 4934802$ the calliper area, whose square root is -7024815 as in the first column; and thus, when there is a decrease of 1-6th, 1-7th, or an increase of 1-10th, 1-9th, \&c. are the numbers determined.

Let fig. 8 represent one quarter of the end of a hewn tree, (as fig. 7 delineated the whole end,) draw the line CG, making the angle $\mathrm{ECG}(=\mathrm{GCH})=45^{\circ}$, and join $\mathrm{FC}$; then in the 20 th line of the table, since the side is to be " 1-5th of the perimeter," half the side (or DF) is to be equal to 4-5ths of the 1-8th part of the perimeter (or DF $+F G$ ), and DF is equal to $4 \mathrm{FG}$; whence we have required to divide an angle of $45^{\circ}$ into two such parts, that the sine of the greater part may be equal to four times the arc of the lesser part. By the help of Dr. Hutton's or Callet's tables, and the method of trial and error, the greater angle will in this case be found $=36^{\circ} 28^{\prime} 59^{\circ} 42^{\prime \prime}=\overline{D C F}$, whose natural cosine is $\$ 8040316$, the number in the first column; and in like manner we proceed when the side is to be 1-6th, 1-7th, \&cc. of the perimeter. The methods of procedure in the remaining cases are sufficiently evident. It may, however, be proper to state, that the prices being reciprocally as the quantities, we have, in the second line, as $\cdot 8: 1:: 100: 125$ shillings per load, as in the last column. 
the diameter $\mathrm{Bb}:$ in like manner let the tree be callipered in the same place, but on the sides or in the directions A a and $A a$, and suppose them 293 and $22 \frac{3}{4}$. Then say, by the rule of three, as $26: 1:: 22^{3}: \cdot 875:$ looking for this number in the first column, we find the nearest number thereto to be 8781018 , and answering thereto in the second column is $1 \cdot 25$, (" $1-4$ th increase,") showing that the square measure of this tree is $1 \cdot 25$ times that of its round measure, or 1-4th part more; and by the third. column it appears that the price per load square measure should be 80-100dths or 8-10ths times that of the price of the same tree per load round measure, exclusive of the cost of hewing, carriage, \&c. Suppose, therefore, the price of the tree in question per load round measure to be 51.109 . or 5.5 , this multiplied by 8 gives $4 \cdot 4$, or 41.8 s. for the price per load square measure or when hewn. For another example: suppose a tree callipered in the middle, on its angles or corners, gave 24 and 24 inches, then 24 inches is the diameter $B \mathrm{~B}$; and that the tree callipered in the same place on its sides gave 19 and 18 inches; the half of the sum of these being 18 ?, or 18.875 inches, is the calliper $A$ a, then as $24: 1:: 18 \cdot 875:: 786:$ the nearest number to this in column the first is $\cdot 7853982$, in which case it appears from column the second that the round measure and square measure are equal, the calliper being equal to $1-4$ th of the cireumference or to the girt; the prices per load should not in this case therefore vary.

Suppose the price per load of hewn timber or of the square measure to be given, and also the proportion which the calliper bears to the diameter, or how many per cent. the former is of the latter; the sccond column will in that case give the proportionate price of the same timber round measure: thus, if hewn timber measured by callipering it be at $71.2 \mathrm{s.} 6 \mathrm{~d}$., or in decimals $7 \cdot 125$ pounds per load; that the cost of hewing and carriage is 21.0 s. $6 \mathrm{~d}$. or 2.025 pounds per load; the difference of these or the net price being $5 \cdot 1$ pounds, and that it be so hewn that the calliper $\mathrm{Aa}$ is 90 per cent. or 90-10odths of the diameier $\mathrm{Bb}$ : looking for -90 in the first column of the table, I find against it in the second column $1 \cdot 313122$, which multiplied by $5 \cdot 1$ gives $6 \cdot 697$ pounds, or $61.13 \mathrm{~s}$. $11 \frac{1}{4} \mathrm{~d}$., the price which this timber ought, independent of profit, to have borne at the place of its growth when round and measured by girting it. A gentleman or his agent having oak timber to dispose of, and being unacquainted with the difference of measures, if offered $51.2 \mathrm{~s}$. per load by a timber dealer, who stated at 
the same time, 6 it will cost me 21. 0s. $6 \mathrm{~d}$. to hew this timber and carry it to London, where it will only fetch 7l. 2 s. 6d. per load," he would instantly conclude what he would think a good bargain; not suspecting that the difference of measure (if hewn, as in the last example, could put nearly $11.12 \mathrm{~s}$. per load, or 31 per cent. into the pocket of the dealer.

It may be proper to add, that the way to examine any lot of hewn timber, with the view of determining to which line of the above table it should be referred, is to take the calliper in inches of several of the trees indiscriminately chosen in the middle or girting place, first on each of their sides, or in the directions $\mathrm{A}$ a and $A a$, and place the results under each other in a column, and next callipering them in the same place but at the corners or in the directions $\mathrm{Bb}$ and $B b$, placing these likewise in a column; then dividing the sum of the first column by the sum of the second column, and carrying the division to three or four places of decimals, the quotient or result is to be sought for in the first column of the table.

Hoping that I have made the above intelligible, and that the table will not be unacceptable to the growers of timber, their agents, and others.

I remain, my lord, your lordship's most obedient and humble servant,

Crown-street, Wesminster, JoHN FAREY.

May 30,1803 .

XXXIX. Parallel of Rome DE L'Isne's and the Abte Haux's Theories of Crystaltography.

[Continued from P. $17^{2}$. ]

Syntursis is grounded, as I mentioned, on the fact, that all well formed crystals art terminated by plane surfaces.

Since there exist primitive forms, there must also be secondary forms, for the one supposes the existence of the other. The secondary forms are such, that sections can he made only parallel to the sides of the primitive; and when the primitive has been produced by these sections, the division being continued the integrant particles are abtained.

The mineralogical analysis descends from the secondary to the primitive form, and from the latter to the integrant particle; just so the mineralogical synthesis ascends from the integrant particle to the primitive, and from thence to 